Portland State University

PDXScholar

Spring 2018

\title{
Accidents Happen: Psychological Empowerment as a Moderator of Accident Involvement and Its Outcomes
}

\author{
Berrin Erdogan \\ Portland State University, berrine@sba.pdx.edu \\ Adnan Ozyilmaz \\ Mustafa Kemal University \\ Talya N. Bauer \\ Portland State University, talyabauer@pdx.edu \\ Onur Emre \\ Yalova University
}

Follow this and additional works at: https://pdxscholar.library.pdx.edu/busadmin_fac

Part of the Business Administration, Management, and Operations Commons, and the Organizational Behavior and Theory Commons

Let us know how access to this document benefits you.

\section{Citation Details}

Erdogan, Berrin; Ozyilmaz, Adnan; Bauer, Talya N.; and Emre, Onur, "Accidents Happen: Psychological Empowerment as a Moderator of Accident Involvement and Its Outcomes" (2018). Business Faculty Publications and Presentations. 90.

https://pdxscholar.library.pdx.edu/busadmin_fac/90

This Post-Print is brought to you for free and open access. It has been accepted for inclusion in Business Faculty Publications and Presentations by an authorized administrator of PDXScholar. Please contact us if we can make this document more accessible: pdxscholar@pdx.edu. 
Accidents Happen: Psychological Empowerment as a Moderator of

Accident Involvement and Its Outcomes

\author{
Berrin Erdogan \\ School of Business Administration \\ Portland State University \\ 631 SW Harrison Street (KMC) \\ Portland, OR 97207 \\ 503-725-3798 \\ berrine@pdx.edu \\ Adnan Ozyilmaz \\ Mustafa Kemal University \\ Tayfur Sokmen Campus \\ School of Economics and Administrative Sciences \\ Department of Business Administration \\ Antakya-Hatay/Turkey 31100 \\ Phone: + 90 (326) 245-5845 \\ E-mail: ozyila@yahoo.com \\ Talya N. Bauer \\ School of Business Administration \\ Portland State University \\ 631 SW Harrison Street (KMC) \\ Portland, OR 97207 \\ 503-725-5050 \\ talyabauer@pdx.edu \\ Onur Emre \\ Department of Business Administration \\ Yalova University \\ IIBF office 416, Cinarcik Yolu \\ Yalova, 77100 TURKEY \\ +902298155155 \\ oemre@yalova.edu.tr
}




\title{
Accidents Happen: Psychological Empowerment as a Moderator of Accident Involvement and Its Outcomes
}

\begin{abstract}
Research in the occupational safety realm has tended to develop and test models aimed at predicting accident involvement in the workplace, with studies treating accident involvement as the starting point and examining its outcomes being more rare. In the current study, we examine the relationship between accident involvement and a series of outcomes drawing upon a learned helplessness theory perspective. Specifically, we predicted that psychological empowerment would moderate the relationship between prior accident involvement and outcomes. We tested our hypotheses on a sample of 392 employees and their 66 supervisors working in an iron and steel manufacturing firm in Southern Turkey, using data collected from employees and their supervisors via four separate surveys. Results suggest that accident involvement was positively related to supervisor rated employee withdrawal, production deviance, and sabotage only when psychological empowerment was low. The results illustrate that workplace accidents have indirect costs in the form of higher withdrawal and maladaptive behaviors, and organizations may inoculate employees against some of these outcomes via higher psychological empowerment. Keywords: Workplace safety, psychological empowerment, withdrawal, counterproductive behaviors.
\end{abstract}




\section{Accidents Happen: Psychological Empowerment as a Moderator of}

\section{Accident Involvement and Its Outcomes}

Safety from workplace accidents and injuries continues to be a challenge for employees and employers alike. In 2014 alone, 13 employees died each day as a result of workplace accidents in the United States (Occupational Safety and Health Administration, 2015). Statistics are equally alarming in the rest of the world with the International Labor Organization (2015) reporting that globally every 15 seconds one employee dies and 153 employees have a workplace accident. Worse yet, research shows that these statistics underestimate the number of accidents and "near misses” experienced on a day-to-day basis (Probst, Brubaker, \& Barsotti, 2008). Despite rising awareness of the role employers play in preventing them by investing in safety measures, accidents and injuries continue to occur. As a result, understanding antecedents of accidents and injuries in the workplace has been of increasing interest to scholars and practitioners alike. Studies, to date, have identified numerous factors contributing to the occurrence of accidents and injuries, including noncompliance with regulations (Neal \& Griffin, 2006), the absence of a positive climate for safety (Zohar, 2000), burnout (Nahrgang, Morgeson, \& Hofmann, 2011), and leadership (Barling, Loughlin, \& Kelloway, 2002).

Reducing and eliminating accidents and injuries is clearly a worthy goal. At the same time, there is increasing recognition that supplementing an "error prevention" approach to safety with an “error management” focus would be beneficial (Frese \& Keith, 2015; van Dyck, Frese, Baer, \& Sonnentag, 2005). According to this perspective, in addition to understanding what causes accidents, it is also essential to understand and manage their aftermath. As a case in point, there is a stream of literature examining the cognitive processes and behaviors following involvement in safety incidents, highlighting how individuals learn from accidents (Drupsteen \& Guldenmund, 
2014). For example, Burke and Signal (2010), in their summary model of workplace safety literature, regard accidents and injuries as precursors to dialogue and reflection. These reflections, in turn, are thought to be related to subsequent safety motivation, and future experiences of accidents and injuries. Beus, Payne, Bergman, and Arthur (2010) showed that experience of injuries is associated with subsequent perceptions of safety climate, confirming that accident involvement may also lead to recalibrations of feelings of safety. Further, research focused on how learning from mistakes may be enhanced through interventions such as after event reviews (Dunn, Scott, Allen, \& Bonilla, 2016; Ellis, Mendel, \& Nir, 2006) and "staff rides" which involve recreating the event coupled with reflection and discussion (Becker \& Burke, 2014).

Despite these advances, there remain two theoretically important gaps in studies examining outcomes of accident involvement. First, outcomes of accident involvement have been primarily limited to safety related cognitions, attitudes, and learning (cf. Barling, Kelloway, \& Iverson, 2003). This is an oversight because the effects of accident involvement may spill over to other aspects of the employment relationship. From a person-centric perspective (Weiss \& Rupp, 2011), being involved in a workplace accident is an aversive and non-routine life event, threatening the person's fundamental need for safety. Even when such events do not result in an injury, employees who were involved in accidents may be affected by the experience, in the form of withdrawal from work or productivity losses. Thus, understanding the outcomes of accident involvement is important to get a more accurate understanding of the true cost of unsafe work, and to more accurately delineate the nomological network of accident involvement. At the same time, scholars point out that it is not exposure to aversive events per se, but experiencing these events while also lacking control over them that creates a sense of helplessness in individuals and drives their 
reactions (Wortman \& Brehm, 1975). As a result, examinations of employee reactions to accident involvement would benefit from adopting a contextual viewpoint.

Second, to our knowledge, no studies have examined which factors may possibly inoculate employees against adverse reactions and help restore normality in the aftermath of being involved in an accident. This is a noteworthy omission because understanding factors that help with management of accidents once they occur complements studies investigating antecedents of accidents. An accident can be a demoralizing, damaging event and it is perhaps normal and expected that accident involvement could be associated with disengaged behaviors. The danger of this possibility is that it could put employees into a negative feedback loop: being involved in an accident may damage morale and erode employee presence at work, which, as prior research has shown, could result in further accidents (e.g., Christian, Bradley, Wallace, \& Burke, 2009). Are there precautions managers may take in the work environment so that being involved in an accident does not necessarily result in outcomes such as withdrawal from work or retaliation against the organization? Managers may find themselves in a situation where they have to deal with the aftermath of occupational accidents, and understanding the conditions under which safety motivation and productivity of these employees remain high is important for the effective management of employees in safety sensitive jobs. This is a significant theoretical gap because the occupational safety literature has not yet examined the conditions under which employees who have been involved in safety related events can retain positive attitudes and behaviors.

In the current study, we develop and test a model of employee reactions to being involved in workplace accidents. We base our model on learned helplessness theory (Seligman, 1975). Consistent with this theory, we predict that employees will react to being involved in workplace accidents more negatively when they have lower levels of control over their jobs, or when they 
experience low levels of psychological empowerment. Learned helplessness theory suggests that employees exposed to aversive events in the absence of control experience three categories of reactions: avoiding the aversive event in the future, withdrawal, and displaying maladaptive behaviors (Maier \& Seligman, 1976). Based on this rationale, we focus on employee effort to avoid future accidents (safety compliance), employee withdrawal, and counterproductive behaviors of production deviance and sabotage as the outcomes in our model.

We aim to make three contributions. First, we add to the occupational safety literature by examining implications of accident involvement for subsequent behaviors. We integrate the learned helplessness and occupational safety literatures and explore the conditions under which reactions to accident involvement are more, or less, damaging to compliance and workplace behaviors. Thus, we provide a theory-based explanation to how employees react to accident involvement, and conditions that can help restore morale and productivity following accidents. Second, we contribute to the psychological empowerment literature. In the past, empowerment has been examined as a predictor of safety outcomes including accidents and injuries (Nahrgang et al., 2011). We propose that in addition to contributing to a safe environment, psychological empowerment also shapes reactions to accidents. Finally, we make a contribution by testing our model in a sample of steel manufacturing employees in Southern Turkey. Steel manufacturing is routinely listed among the most dangerous jobs in the US (Time Inc., 2014). Turkey is one of the top 10 steel producers in the world (World Steel Association, 2015) and the least safe country for workers in Europe, with over 1,800 deaths due to workplace accidents and occupational illnesses in 2014 (İşçi Sağlığg ve İş Güvenliği Meclisi, 2017). Thus, our study was conducted in an understudied region, in a setting where serious accidents are common, and the threat of accidents is high and salient. 


\section{Theoretical Background and Hypotheses}

\section{Learned Helplessness Theory}

Seligman (1972; 1975) proposed learned helplessness theory as an explanation for why exposure to unpleasant or aversive stimuli results in differential reactions in victims. Findings suggest that there is a marked variation in reactions to undesirable events depending on the degree to which the victim has control over the situation. In general, the absence of control results in a belief that future action is futile and there is not much the person can do to alter future course of events. As a result, aversive events, coupled with feelings of absence of control, have implications for future behaviors and the mental state of the individual.

Maier and Seligman (1976) noted that those who are exposed to aversive stimuli or shocks under the low control condition react in three predictable ways. First, their motivation to avoid the aversive event in the future is typically lower. This is because individuals come to view their actions as disconnected from future consequences (Peterson \& Seligman, 1983). Second, they mentally disengage from the environment, responding in passive and withdrawn ways such as behavioral withdrawal and cognitive distancing (Mikulincer, 2013). Finally, they suffer emotional distress and display maladaptive behaviors. Even though learned helplessness has long been associated with withdrawal symptoms, there is also evidence that it is associated with anger (Roth \& Kubal, 1975). For example, research has shown that exposure to aggressive supervisory behaviors in a work context coupled with low control resulted in deviant behaviors and displaced aggression (Mitchell \& Ambrose, 2012) suggesting that a third alternative way in which individuals may react to learned helplessness is through retaliatory behaviors.

Thus, based on learned helplessness theory, we predict that accident involvement will be associated with negative outcomes to the degree to which employees perceive that they lack 
control. In the management literature, ability of employees to shape their own environment is often studied under the psychological empowerment construct (Spreitzer, 1995). Empowerment reflects the psychological sense that the person has power, because they have the ability to control their environment. Psychological empowerment consists of the perception that one can perform their tasks competently, have autonomy to decide how to do their jobs, and their behavior makes a difference (Thomas \& Velthouse, 1990). Empowerment allows employees to cope with stressors more constructively (Erdogan \& Bauer, 2009; Fisher, 2014) and enables employees to adjust to the demands of their jobs in uncertain environments (Firth, Chen, Kirkman, \& Kim, 2014).

Psychological empowerment has been identified as an important predictor of attitudes, performance, and turnover intentions (Seibert, Wang, \& Courtright, 2011). In the occupational safety literature, psychological empowerment has been shown to be related to subsequent safety outcomes. For example, in a sample of hospital employees, psychological empowerment was related to safety participation (Ford \& Tetrick, 2011). Further, empowerment within teams negatively predicted unsafe behaviors and accidents (Hechanova-Alampay \& Beehr, 2001).

It is our contention that in addition to contributing to overall safety, employee empowerment will interact with accident involvement to predict employee reactions. Accident involvement is likely to trigger symptoms of helplessness for employees who experience low empowerment, because the employee feels little control over work. For these employees, involvement in an accident is likely to be related to lower likelihood to engage in safety compliance, higher likelihood to withdraw, and engagement in counterproductive behaviors.

\section{Outcomes of Accident Involvement as Moderated by Psychological Empowerment}

Early learned helplessness experiments confirmed that when an individual was exposed to unpleasant stimuli, those who engaged in behaviors to avoid it in the future tended to be those who 
had control in earlier rounds of the experiment (Maier \& Seligman, 1976), whereas those who experienced the aversive event in the absence of control showed no such positive reactions. It is thought that the combination of lack of control and aversive experiences has negative motivational implications because the person does not expect such efforts to yield positive outcomes (Frese \& Fay, 2001). In organizational settings, researchers have proposed that the experience of learned helplessness resulting from negative events under low control would result in lack of interest in altering one’s behavior (George \& Jones, 2001). In the context of safety, this would suggest that employees who were involved in an accident are more likely to behave in ways to avoid an accident in the future to the degree to which they feel empowered. Safety compliance refers to complying with safety regulations and includes behaviors such as following safety rules, encouraging coworkers to be safe, taking proactive actions to increase safety, and escalating safety risks to one’s supervisor (Clarke, 2006; Neal \& Griffin, 2006). In other words, the motivation to avoid accidents in the future will be higher among those who experienced an accident under high empowerment.

Hypothesis 1. Accident involvement and psychological empowerment will interact to predict employee safety compliance such that accident involvement will be positively related to compliance when empowerment is high, but will be unrelated when empowerment is low.

Second, withdrawal is thought to be a key reaction to learned helplessness (Martinko, Gundlach, \& Douglas, 2002). Individuals who experience aversive events along with a lack of control withdraw from the context and reduce their meaningful involvement in tasks (Baum \& Gatchel, 1981). One type of withdrawal is to exit the situation. For example, past research on occupational safety has shown that being injured at work is positively related to turnover intentions 
(McCaughey et al., 2012; Young \& Corsun, 2009). However, employees can also withdraw from their jobs without physically leaving. In fact, researchers contended that withdrawal without leaving is a more probable reaction compared to exit given that employees suffering from helplessness tend to see their current work situation as less likely to change, resulting in behaviors that indicate reduced effort on the job (Hulin, Roznowski, \& Hachiya, 1985; Zimmerman, Swider, Woo, \& Allen, 2016). Withdrawal behaviors include coming to work late, staying home claiming to be sick, and taking long breaks (Spector et al., 2006). Therefore, we predict that withdrawal is a potential response to accident involvement when coupled with low empowerment.

Hypothesis 2. Accident involvement and psychological empowerment will interact to predict withdrawal such that accident involvement will be positively related to withdrawal when empowerment is low, but will be unrelated when empowerment is high.

Finally, the theory of learned helplessness predicts that employees who experience aversive events under conditions of low control would have more emotional disruption and therefore behave in ways that are more destructive and maladaptive (Maier \& Seligman, 1976). Early on, studies of learned helplessness have shown that when experiencing uncontrollable and aversive stimuli, victims showed symptoms consistent with depression and withdrawal, and that they were less likely to behave in aggressive ways. However, in contrast to these prior findings, subsequent work suggests that one symptom of learned helplessness is feelings of aggression and resentment, and engaging in hostile and aggressive actions in a covert way (Berkowitz, 1983). In other words, we expect that in addition to withdrawing from the situation, employees may engage in covert behaviors that indicate anger and resentment.

Counterproductive behaviors are ways in which employees display negative emotions and covert aggressive behaviors at work and they include production deviance (purposefully ignoring 
instructions or slowing down work) and sabotage (including behaviors such as harming or wasting the equipment and organizational resources). Research has shown that production deviance serves as a coping mechanism for emotionally exhausted employees (Krischer, Penney, \& Hunter, 2010) and production deviance and sabotage have been shown to be related to anger (Spector et al., 2006). As a result, we predict that accident involvement will have implications for counterproductive work behaviors in the form of production deviance and sabotage.

Hypothesis 3. Accident involvement and psychological empowerment will interact to predict production deviance (Hypothesis 3a) and sabotage (Hypothesis 3b) such that accident involvement will be positively related to production deviance and sabotage for employees who have low levels of empowerment, whereas the relationship will be nonsignificant for employees who have high empowerment.

\section{Method}

\section{Sample and Procedures}

We collected data from employees and supervisors of a leading iron and steel manufacturer in Southern Turkey. The company produces iron bars, reinforcing bars, and earthquake resistant steel, and provides harbor services. Our study took place in departments throughout the company including the blooming mill, electricity maintenance, steelworks, quality assurance, supporting units, machine maintenance, and harbor services.

We collected employee data via three surveys (T1, T2, and T3) distributed one month apart, followed by one supervisor survey (T4), taking place one month following the completion of the last employee survey. The Time 1 (T1) survey included demographics and several control variables. The Time 2 (T2) survey included a measure of psychological empowerment. The Time 3 (T3) survey measured accident involvement, the safety climate (control), and safety compliance. 
Finally, the Time 4 (T4) survey included a supervisor measure of employee withdrawal, production deviance, and sabotage. Surveys were in a paper-and-pencil format. Packets were distributed to all employees performing safety-sensitive jobs $(n=838)$. Each employee was assigned a unique code written on each survey in order to facilitate the matching process. Supervisors were given the name of the employee and an associated code, and were asked to only write the code on their survey. Employees returned their completed surveys in sealed envelopes into sealed collection boxes. These boxes were collected by the second author.

Initially, 838 surveys were distributed, and 715 were returned (response rate $=85 \%$ ). The second survey was distributed to 826 employees and 656 were received (response rate $=79 \%$ ). The third survey was distributed to 820 and 498 were returned (response rate $=61 \%$ ). Finally, we received surveys from 86 supervisors. After dropping surveys with missing time periods and data, we retained 392 dyads (392 employees and 66 supervisors), for a final overall response rate of 47\%. The 392 employees were 99\% male, 36.68 years of age $(\mathrm{SD}=8.46)$, had 9.74 years $(\mathrm{SD}=$ 7.94) of organizational tenure, and were mostly high school graduates (50.8\%). Supervisors were 43.13 years of age $(\mathrm{SD}=8.48)$, $98 \%$ were male, and had worked in the organization for 16.85 years $(S D=9.26)$. A majority of the supervisors were high school graduates $(51.8 \%)$.

\section{Measures}

All measures were rated on a 5-point Likert scale ranging from 1 (strongly disagree) to 5 (strongly agree) unless otherwise noted. All items were translated into Turkish following established back-translation procedures as outlined by Brislin (1970).

Accident involvement. Employees were asked to report the number of times they were involved in an accident in the past six months and were presented with a checklist to help them remember their involvement. We focused on the prior six-month period to increase the probability 
of recall. The checklist was adapted from Barling et al.'s (2002) safety-related incidents scale. Sample items included "Something fell on me” and "Had my hand in contact with a blade.” We modified the items to apply to a manufacturing setting. The most frequently occurring events were hurting oneself while lifting something heavy (43 employees), burning one's hand by touching something hot (22 employees), and spilling something hot on one’s body (20 employees). Overall, 19\% of employees (74 employees) had been involved in at least one safety incident in the past 6 months. We operationalized accident involvement as $0=$ No involvement in an accident in the past six months, 1 = involved in at least one accident in the past six months.

Of those 74 employees who reported having been involved in an accident in the past six months, $81 \%$ reported $1-10$ accidents. The remainder $(n=14)$ reported numbers ranging between 11 and 128. Using the method described by Moore and McCabe (1999), in our dataset employees reporting 14 or more accidents may be regarded as outliers. The exclusion of cases who reported 14 or more accidents (12 employees) did not result in any changes in our reported results. Further, our operationalization of accident involvement as a $0-1$ dichotomy would alleviate any concern regarding inflated reports of accidents. Therefore, we report the results with all respondents.

Psychological empowerment. We measured empowerment using the 12-item scale developed by Spreitzer (1995). A sample item was "I have significant autonomy in determining how I do my job" $(\alpha=.88)$.

Safety compliance. Employees reported their compliance with safety procedures using an 11-item scale developed by Hayes, Perander, Smecko, and Trask (1998). A sample item was “I follow all safety procedures regardless of the situation I am in” $(\alpha=.80)$. 
Employee withdrawal. Supervisors rated employee withdrawal using four items from Spector et al. (2006). A sample item was “Takes longer breaks than he/she is allowed to take.” $(\alpha=$ $.80)$.

Production deviance. Supervisors rated employee production deviance using three items from Spector et al. (2006). A sample item was "Purposely fails to follow instructions" $(\alpha=.81)$.

Sabotage. Supervisors rated employee sabotage using three items from Spector et al. (2006). A sample item was “Purposely wastes employer's materials and supplies” $(\alpha=.87)$.

Control variables. We controlled for the personality trait of risk-taking, employee level in the hierarchy, organizational tenure, and education measured at T1, and safety climate measured at T3. Risk-taking was controlled because employees with higher risk-taking orientation may behave less safe, and experience more accidents (Westaby \& Lowe, 2005). Five items from Westaby and Lowe (2005) were used to assess employee risk-taking orientation. A sample item was "I get my job done faster by taking risks" $(\alpha=.68)$. Safety climate was an important control because the relationship between accident involvement and outcomes may simply reflect the established relationship between safety climate and outcomes (e.g., Clarke, 2010). Employees reported their perceptions of safety climate using the 10-item scale by Zohar (2000). A sample item was "My supervisor approaches workers during work to discuss safety issues” ( $\alpha=.85$ ). Level, education, and tenure were controlled, because employees who work in higher levels, highly educated employees, or those who have been in the organization for a long time may both feel empowered and report more positive attitudes and behaviors, providing an explanation for the observed relationships. Level was coded as 1-3, with 1 representing the lowest level employees. Tenure was in years. Education was coded as $0=$ less than elementary school diploma to $9=$ graduate degree 


\section{Results}

Means, standard deviations, and correlations are presented in Table 1. Due to the high correlation among supervisor rated outcomes, we conducted a confirmatory factor analysis. The baseline model specifying distinct factors for the three outcomes had modest fit $\left(\chi^{2}=167.70, d f=\right.$ 32, $\mathrm{CFI}=.90, \mathrm{RMSEA}=.10$ ) but was superior to the alternative nested models where production deviance and sabotage $\left(\Delta \chi^{2}=103.22, \Delta d f=2, p<.01\right)$, production deviance and withdrawal $\left(\Delta \chi^{2}=\right.$ 132.14, $\Delta d f=2, p<.01)$, and sabotage and withdrawal $\left(\Delta \chi^{2}=23.82, \Delta d f=2, p<.01\right)$, were specified to fall under the same factor, as well as a model where a single factor was specified for all three outcomes $\left(\Delta \chi^{2}=149.97, \Delta d f=3, p<.01\right)$.

Due to the nested nature of our data where 392 employees reported to 66 supervisors, we tested our hypotheses using multilevel regression procedures in Mplus 7. Specifically, because employees worked within intact groups and experienced similar work environments, responses obtained from employees reporting to the same supervisor would likely share substantial variation. The intraclass correlations (ICCs) for the dependent variables were .20, .32, .41, and .45 for safety compliance, employee withdrawal, production deviance, and sabotage, respectively, suggesting that using multilevel methodology was warranted.

When testing all hypotheses, we specified two models for each dependent variable. The first model contained the control variables, and the main effects of accident involvement and psychological empowerment at within and between levels. In Model 2, we added the interaction term to both levels. A significant coefficient for the interaction term at the within level, coupled with a significant reduction in the deviance statistic between Model 1 and Model 2 were interpreted as support for a hypothesis. When a significant interaction was observed, we plotted the 
interaction at one $S D$ above and below the mean and probed whether each slope differed from zero following Cohen, Cohen, West, and Aiken (2003).

Even though we did not hypothesize main effects, we first examined the results to see whether accident involvement had any significant relations with the outcomes. Before we added the interaction term, accident involvement was positively related to employee withdrawal $(\gamma=.14$, $S E=.07, t=1.98, p<.05)$. Further, accident involvement was positively related to production deviance $(\gamma=.15, S E=.07, t=2.09, p<.05)$. However, given that we expected interactions with psychological empowerment, interpreting these main effects would not be appropriate.

The results for our hypotheses presented in Table 2 indicate no support for Hypothesis 1. Psychological empowerment was positively related to safety compliance, but there was no interaction with accident involvement. Other predictors of safety compliance included low levels of risk taking personality, and safety climate perceptions. The results for Hypothesis 2 are presented in Table 2. Adding the interaction term resulted in a significant reduction in deviance for employee withdrawal, and the interaction term was significant. As shown in Figure 1, accident involvement had a positive relationship with employee withdrawal behaviors when empowerment was low (simple slope: $\gamma=.30, S E=.10, t=3.11, p<.01$ ). When empowerment was high, there was no relationship (simple slope: $\gamma=-.03$, $S E=.07, t=-.40, p>.05$ ).

The results for Hypotheses 3a and $3 b$ are presented in Table 3. The coefficient of the interaction term is significant for both production deviance and sabotage. Adding the interaction term to the equation reduced deviance only for production deviance, and not for sabotage, indicating support for Hypothesis 3a, but not for 3b. At the same time, the interaction term was significant for both production deviance and sabotage, so we plotted and explored the nature of both interactions. Plots of the interactions (Figures 2a and 2b) and simple slope analyses suggested 
that accident involvement was positively related to production deviance when empowerment was low $(\gamma=.31, S E=.10, t=3.30, p<.01)$ and unrelated when empowerment was high $(\gamma=-.03, S E$ $=.09, t=-.31, p>.05)$. Further, accident involvement was positively related to sabotage when empowerment was low $(\gamma=.17, S E=.05, t=3.17, p<.01)$ and unrelated when empowerment was high $(\gamma=.00, S E=.06, t=.10, p>.05)$. These results provided support for Hypotheses 3a.

For Hypothesis 3b, the pattern of the interaction with respect to sabotage included some surprising relationships. On the one hand, these results support the learned helplessness explanation: when empowerment is low, accident involvement is related to higher levels of sabotage. In other words, individuals who experience low empowerment are disinclined to engage in sabotage, which is a tendency that disappears when they experience an accident. On the other hand, these results indicate that high empowerment is associated with greater likelihood of engaging in sabotage. We discuss these findings in more detail in the discussion section.

\section{Supplemental Analyses}

Our main analyses treat all accident involvement equally. However, accident severity may affect the ability of empowerment to neutralize the effects of accident involvement. For example, Burke and Signal (2010) observed that reactions to accidents resulting in injuries could differ from those without injuries. To test for this possibility, we performed additional analyses. As part of our T3 questionnaire, employees had reported (using an instrument by Barling et al., 2002) whether they had experienced any of the eight types of injuries in the past six months. Of the 74 employees who had been involved in an accident in the past six months, 46 also reported an injury. We recoded accident involvement as $0=$ did not experience an accident in the past six months, $1=$ experienced an accident not resulting in an injury, and $2=$ experienced an accident resulting in an injury. This null-based coding scheme is appropriate for reflecting both the absence of a 
phenomenon and its presence with varying degrees of severity (Feinstein, 1996). The results were consistent with the main results such that the interaction term showed the same pattern of relations with production deviance $(\gamma=-.13, S E=.06, t=-2.20, p<.05)$, withdrawal $(\gamma=-.12, S E=.04, t=$ -3.23, $p<.01)$, and sabotage $(\gamma=-.09, S E=.04, t=-2.10, p<.05)$ and remained unrelated to safety compliance $(\gamma=-.04, S E=.03, t=-1.08, p>.05)$.

Given the correlated outcomes, an alternative test of our model is through multilevel path analysis. When we specified our model using this approach, the number of parameters exceeded number of clusters, deeming estimates unreliable. Modifying our model so that all predictors were entered at the within, but not between level yielded results parallel with the main results we report, with the interaction term having similar relations to outcomes except for sabotage which had a slightly higher $p$ value $(\gamma=-.06, p>.05$ for safety compliance, $\gamma=-.24, p<.01$ for withdrawal, $\gamma=$ $-.25, p<.05$ for production deviance, and $\gamma=-.11, p=.08$ for sabotage). These additional results further suggest that out of the three significant interactions, sabotage is the least stable one.

Finally, we tested the possibility that instead of empowerment, safety climate may act as a buffer of accident involvement. Even though empowerment is a direct measure of control over one's work, employees may also have elevated sense of control when they perceive safety climate. When we tested our interactions using safety climate as moderator, the interaction was significant only with respect to production deviance $(\gamma=-.10, p<.05)$, with high safety climate neutralizing the positive relation between accident involvement and production deviance. In other words, safety climate was a weak surrogate for the control afforded by psychological empowerment.

\section{Discussion}

Given the prevalence of workplace accidents, the limited understanding of accident involvement outcomes is surprising. To date, the occupational safety literature tended to focus on 
predictors of accidents and injuries (Nahrgang et al., 2011). Adopting an error management in addition to error prevention perspective (Frese \& Keith, 2015) in the workplace safety context would suggest that we need more systematic investigations of outcomes of accident involvement. So far, these investigations focused on cognitive and behavioral reactions to accidents in the form of reflection, and how accident involvement could result in learning, safety motivation, and reduction in subsequent accidents (Burke \& Signal, 2010; Drupsteen \& Guldenmund, 2014). The experience of accident involvement and how it affects a broader set of workplace behaviors, and the conditions under which these occur are understudied yet important topics.

Drawing from learned helplessness theory (Seligman, 1975), we examined psychological empowerment as a factor that could mitigate the negative implications of accident involvement on safety compliance, withdrawal, production deviance, and sabotage. Accident involvement was positively related to manager rated withdrawal and production deviance. Further, the relationship between accident involvement and outcomes was conditional on psychological empowerment such that employees who experienced lower empowerment reacted to accidents in the form of higher withdrawal, production deviance, and sabotage. No main effects or moderated effects were observed for safety compliance. The results suggest that experiencing an accident and perceiving low levels of control over one's job and environment were related to a situation where employees were more withdrawn and engaged in covert types of retaliation, but did not affect employees’ subsequent efforts to avoid future accidents in the form of safety compliance.

\section{Theoretical Implications}

Theoretically, our results suggest that accident involvement is a meaningful predictor of workplace attitudes and behaviors controlling for safety climate. Experiencing accidents in a context where employees feel low empowerment was associated with withdrawal and maladaptive 
behaviors. Past research on errors shows that especially when employees reflect and discuss their mistakes and are guided through the process, they learn from them (e.g., Ellis et al., 2006; Heimbeck, Frese, Sonnentag, \& Keith, 2003). Our findings add to this literature by showing that a lack of control may result in a different kind of learning, resulting in outcomes that are consistent with a learned helplessness theory explanation.

Further, our results point to the important role psychological empowerment plays in buffering the experience of accidents and preventing serious damage to workplace behaviors and attitudes. To date, studies of workplace safety have shown that psychological empowerment is positively related to safety performance (e.g., Hechanova-Alampay \& Beehr, 2001). Our study points out to an additional path by which psychological empowerment is relevant to workplace safety: To those employees experiencing low empowerment, experiencing an accident is accompanied by higher withdrawal from the job, and behaving in ways that may be interpreted as retaliation. It is likely that those employees who feel empowered do not experience a sense of helplessness that may accompany a workplace accident. When trying to understand differing reactions to accidents by organizational agents and insiders, it seems important to consider the role of psychological empowerment, as those who feel in control of their jobs seem not to differ from those who did not experience an accident with respect to their work attitudes and behaviors.

One of our hypotheses did not receive any support, and would benefit from further investigation. Specifically, accident involvement had no relationship with safety compliance. It is important to note that self-reported safety compliance was quite high (with an average of 4.29), so social desirability may be a concern. Alternatively, because the cost of being unsafe is high and directly affects employees, employees show high levels of safety compliance regardless of their 
involvement in an accident. Future research would benefit from examining more objective recordings of safety incidents and subsequent safety compliance to provide a stronger test.

The finding that empowerment is positively related to sabotage is an interesting and unexpected finding, which differentiates sabotage from other counterproductive behaviors we examined. Sabotage is a risky activity and includes behaviors such as damaging equipment and property and therefore low empowerment may prevent individuals from displaying higher levels of this behavior. These results are consistent with Mackey, Frieder, Perrewé, Gallagher, and Brymer’s (2015) finding that high empowerment was associated with higher counterproductive behaviors. In other words, our findings suggested that more work on the dark side of empowerment is an important avenue of future research.

\section{Practical Implications}

Our results suggest that accidents have hidden costs. In addition to well-known effects of accidents in the form of medical expenses, higher insurance premiums, and time lost, accidents have the potential to interfere with employer-employee relationship. Employees who have been in an accident withdraw from their work by engaging in lateness or absenteeism, purposefully slow down production, and even engage in sabotage. Accounting for these negative effects are important both to understand the true cost of unsafe workplaces, and to prevent future accidents. Our results also suggest that psychological empowerment may serve as a way to inoculate employees against the harmful effects. Employees who feel empowered react to accident involvement differently from those who perceive lower levels of empowerment. The sense that one has control over their own work and impact on the environment seems to be the key difference between those who experience withdrawal and high counterproductive behaviors and those who do not. Therefore, empowerment may be a promising candidate as a safety intervention. 
Our results speak to the possibility that how managers prevent accidents and how they manage accident aftermath may require complimentary but different approaches. A key tool for accident prevention is fostering a safety climate (Clarke, 2006). The most commonly used measures of safety climate (e.g., Zohar, 2000) focus on actions and attitudes of managers, such as managers paying close attention to safety, approaching employees frequently about safety, and keeping track of safety problems. Some of this emphasis on supervisor behaviors, if taken too far, could be at tension with psychological empowerment. Our findings suggest that while safety climate is critically important, organizations would benefit from cultivating it without impeding on psychological empowerment. During the accident aftermath, reinforcing felt empowerment by involving employees in safety decisions, seeking their input, and allowing them to suggest changes may be helpful in tempering the negative outcomes of accident involvement.

\section{Potential Limitations and Future Research Directions}

As in any field study, our study has potential limitations. First, we were unable to include an objective metric of accident involvement and had to rely in employee recollections. We feel confident that given a time period of six months and the use of a checklist, employees should be able to recollect whether they had been involved in an accident. Further, not all accident involvement would be reflected in organizational records (Probst et al., 2008), particularly in a developing country context where enforcement of reporting requirements are lax. At the same time, due to the retrospective nature of our accident involvement data, our sample would lack employees who experienced an accident and later left the organization. We included an accident involvement measure in the T3 employee survey, which was the closest survey to when we measured study outcomes from supervisor's perspective at T4. This approach meant that we were unable to capture any accidents that may have occurred in the month between T3 and T4. 
Supplementing these results with actual accident and injury records would be an important extension of our findings.

Our sample is from Southern Turkey, an underrepresented region in past workplace safety research. Before generalizing to other samples, it is important to consider the implications of our sample for our research questions. Steel manufacturing is a heavy manufacturing industry, involving lifting heavy materials, and working with extremely hot materials and toxins under noisy conditions, making this setting an appropriate and important one to explore the effects of accidents. According to Turkish Union of Chambers and Commodity Exchanges, the industry is estimated to employ over 200,000 employees as of 2013 (Türkiye Odalar ve Borsalar Birliği, 2013), increasing the relevance and practical importance of these results. Further, psychological empowerment has been previously studied in Turkey, with results suggesting that employees react positively and benefit from empowerment (e.g., Erdogan \& Bauer, 2009; Gumusluoglu \& Ilsev, 2009). Still, it is important to explore generalizability to other contexts.

We did not have a measure of coworker observations of accidents. As such, our results only speak to experienced and reported accidents, but not necessarily observed accidents. One future avenue to consider is whether observed accidents result in similar outcomes to experienced accidents. In other words, do the learned helplessness effects occur only during direct involvement in an accident? Or do observations lead to similar outcomes? If they do, does empowerment act as a buffer of these effects, or are there other moderators, such as the attributions made for the accident? The situational and personal relevance of the coworker may also matter (Gyekye \& Salminen, 2006) and may engender learned helplessness effects. In other words, delineating when coworker accident involvement could result in learned helplessness effects is an important research area, given that for any accident, there may be many more coworkers who witness it. 
Our measure of accident involvement did not capture the severity of accidents. We performed supplemental analyses considering whether the employee had been injured, but we do not have a measure of accident-level data on how severe each incident was. Our sample came from one organization studied over four months, and despite the non-negligible number of employees who reported having experienced accidents in the prior six months, it is not a sample of employees having challenges with return to work. While we found empowerment to neutralize the positive effects of accident involvement on outcomes, it is unclear whether empowerment would be similarly helpful in cases of accidents resulting in acute injuries, job transfers or restrictions, and extended time away from work. Replicating these results in a sample of workers who recently experienced acute injuries and had return to work challenges is important.

In conclusion, we set out to examine the implications of accident involvement for employee attitudes and behaviors. Accident involvement has indirect costs in the form of higher withdrawal from the organization, higher production deviance, and sabotage. At the same time, organizations may be able to inoculate their employees against the harmful effects of accident involvement. Psychological empowerment directly contributes positively to safety compliance, and at the same time alleviates the negative implications of accident involvement on withdrawal, production deviance, and sabotage. The results indicate that the occupational safety literature would benefit from further investigations of accident involvement as a predictor, and psychological empowerment as a way to prevent learned helplessness in the workplace. 


\section{References}

Barling, J., Kelloway, E. K., \& Iverson, R. D. (2003). High-quality work, job satisfaction, and occupational injuries. Journal of Applied Psychology, 88, 276-283. doi: 10.1037/00219010.88 .2 .276

Barling, J., Loughlin, C., \& Kelloway, E. K. (2002). Development and test of a model linking safety-specific transformational leadership and occupational safety. Journal of Applied Psychology, 87, 488-496. doi: 10.1037/0021-9010.87.3.488

Baum, A., \& Gatchel, R. J. (1981). Cognitive determinants of reaction to uncontrollable events: Development of reactance and learned helplessness. Journal of Personality and Social Psychology, 40, 1078-1089. doi: 10.1037//0022-3514.40.6.1078

Becker, W. S., \& Burke, M. J. (2014). Instructional staff rides for management learning and education. Academy of Management Learning \& Education, 13, 510-524. doi: 10.5465/amle.2012.0306

Berkowitz, L. (1983). Aversively stimulated aggression: Some parallels and differences in research with animals and humans. American Psychologist, 38, 1135-1144. doi: 10.1037/0003066X.38.11.1135

Beus, J. M., Payne, S. C., Bergman, M. E., \& Arthur, W. (2010). Safety climate and injuries: An examination of theoretical and empirical relationships. Journal of Applied Psychology, 95, 713-727. doi: 10.1037/a0019164

Brislin, R. W. (1970). Back-translation for cross-cultural research. Journal of Cross-cultural Psychology, 1, 185-216. doi: https://doi.org/10.1177/135910457000100301 
Burke, M. J., \& Signal, S. M. (2010). Workplace safety: A multilevel interdisciplinary perspective. Research in Personnel and Human Resources Management, 29, 1-47. doi: 10.1108/S07427301(2010)0000029003

Christian, M. S., Bradley, J. C., Wallace, J. C., \& Burke, M. J. (2009). Workplace safety: A metaanalysis of the roles of person and situation factors. Journal of Applied Psychology, 94, 1103-1127. doi: 10.1037/a0016172

Clarke, S. (2006). The relationship between safety climate and safety performance: A metaanalytic review. Journal of Occupational Health Psychology, 11, 315-327. doi: 10.1037/1076-8998.11.4.315

Clarke, S. (2010). An integrative model of safety climate: Linking psychological climate and work attitudes to individual safety outcomes using meta-analysis. Journal of Occupational and Organizational Psychology, 83, 553-578. doi: 10.1348/096317909X452122

Cohen, J., Cohen, P., West, S. G., \& Aiken, L. S. (2003). Applied multiple correlation/regression analysis for the behavioral sciences. Mahwah, NJ: Lawrence Erlbaum Associates.

Drupsteen, L., \& Guldenmund, F. W. (2014). What is learning? A review of the safety literature to define learning from incidents, accidents, and disasters. Journal of Contingencies and Crisis Management, 22, 81-96. doi: 10.1111/1468-5973.12039

Dunn, A. M., Scott, C., Allen, J. A., \& Bonilla, D. (2016). Quantity and quality: Increasing safety norms through after action reviews. Human Relations, 69, 1209-1232. doi: $10.1177 / 0018726715609972$

Ellis, S., Mendel, R., \& Nir, M. (2006). Learning from successful and failed experience: The moderating role of kind of after-event review. Journal of Applied Psychology, 91, 669-680. doi: 10.1037/0021-9010.91.3.669 
Erdogan, B., \& Bauer, T. N. (2009). Perceived overqualification and its outcomes: The moderating role of empowerment. Journal of Applied Psychology, 94, 557-565. doi: 10.1037/a0013528

Feinstein, A. R. (1996). Multivariable analysis: An introduction. Yale University Press: Chelsea, MI.

Firth, B. M., Chen, G., Kirkman, B. L., \& Kim, K. (2014). Newcomers abroad: Expatriate adaptation during early phases of international assignments. Academy of Management Journal, 57, 280-300. doi: 10.5465/amj.2011.0574

Fisher, D. M. (2014). A multilevel cross-cultural examination of role overload and organizational commitment: Investigating the interactive effects of context. Journal of Applied Psychology, 99, 723-736. doi: 10.1037/a0035861

Ford, M. T., \& Tetrick, L. E. (2011). Relations among occupational hazards, attitudes, and safety performance. Journal of Occupational Health Psychology, 16, 48-66. doi: 10.1037/a0021296

Frese, M., \& Fay, D. (2001). Personal initiative: An active performance concept for work in the $21^{\text {st }}$ century. Research in Organizational Behavior, 23, 133-187. doi: 10.1016/S01913085(01)23005-6

Frese, M., \& Keith, N. (2015). Action errors, error management, and learning in organizations. Annual Review of Psychology, 66, 661-687. doi: 10.1146/annurev-psych-010814-015205

George, J. M., \& Jones, G. R. (2001). Towards a process model of individual change in organizations. Human Relations, 54, 419-444. doi: 10.1177/0018726701544002

Gumusluoglu, L., \& Ilsev, A. (2009). Transformational leadership, creativity, and organizational innovation. Journal of Business Research, 62, 461-473. doi: 10.1016/j.jbusres.2007.07.032 
Gyekye, S. A., \& Salminen, S. (2006). The self-defensive attribution hypothesis in the work environment: Co-workers’ perspectives. Safety Science, 44, 157-168. doi: 10.1016/j.ssci.2005.06.006

Hayes, B. E., Perander, J., Smecko, T., \& Trask, J. (1998). Measuring perceptions of workplace safety: Development and validation of the work safety scale. Journal of Safety Research, 29, 145-161. doi: 10.1016/S0022-4375(98)00011-5

Hechanova-Alampay, R., \& Beehr, T. A. (2001). Empowerment, span of control, and safety performance in work teams after workforce reduction. Journal of Occupational Health Psychology, 6, 275-282. doi: 10.1037/1076-8998.6.4.275

Heimbeck, D., Frese, M., Sonnentag, S., \& Keith, N. (2003). Integrating errors into the training process: The function of error management instructions and the role of goal orientation. Personnel Psychology, 56, 333-361. doi: 10.1111/j.1744-6570.2003.tb00153.x

Hulin, C. L., Roznowski, M., \& Hachiya, D. (1985). Alternative opportunities and withdrawal decisions: Empirical and theoretical discrepancies and an integration. Psychological Bulletin, 97, 233-250. doi: 10.1037/0033-2909.97.2.233

International Labor Organization (2015). Safety and health at work. Retrieved on November 25, 2015 from http://www.ilo.org/global/topics/safety-and-health-at-work/lang--en/index.htm İşçi Sağlığı ve İş Güvenliği Meclisi [Worker health and work safety council] (May 2, 2016). Rakamlarla Türkiye'de iş kazaları ve işçi ölümleri [Workplace accident and employee death statistics in Turkey]. Retrieved on January 4, 2017 from http://www.sivilsayfalar.org/rakamlarla-turkiyede-is-kazalari-ve-isci-olumleri/ 
Krischer, M. M., Penney, L. M., \& Hunter, E. M. (2010). Can counterproductive work behaviors be productive? CWB as emotion-focused coping. Journal of Occupational Health Psychology, 15, 154-166. doi: 10.1037/a0018349

Mackey, J. D., Frieder, R. E., Perrewé, P. L., Gallagher, V. C., \& Brymer, R. A. (2015). Empowered employees as social deviants: The role of abusive supervision. Journal of Business and Psychology, 30, 149-162. doi: 10.1007/s10869-014-9345-X

Maier, S. F., \& Seligman, M. E. (1976). Learned helplessness: Theory and evidence. Journal of Experimental Psychology: General, 105, 3-46. doi: 10.1037/0096-3445.105.1.3

Martinko, M. J., Gundlach, M. J., \& Douglas, S. C. (2002). Toward an integrative theory of counterproductive workplace behavior: A causal reasoning perspective. International Journal of Selection and Assessment, 10, 36-50. doi: 10.1111/1468-2389.00192

McCaughey, D., McGhan, G., Kim, J., Brannon, D., Leroy, H., \& Jablonski, R. (2012). Workforce implications of injury among home health workers: Evidence from the National Home Health Aide Survey. The Gerontologist, 52, 493-505. doi: 10.1093/geront/gnr133

Mikulincer, M. (2013). Human learned helplessness: A coping perspective. New York: Springer Science \& Business Media.

Mitchell, M. S., \& Ambrose, M. L. (2012). Employees’ behavioral reactions to supervisor aggression: An examination of individual and situational factors. Journal of Applied Psychology, 97, 1148-1170. doi: 10.1037/a0029452

Moore, D. S. \& McCabe, G. P. (1999). Introduction to the practice of statistics. New York: W. H. Freeman. 
Nahrgang, J. D., Morgeson, F. P., \& Hofmann, D. A. (2011). Safety at work: A meta-analytic investigation of the link between job demands, job resources, burnout, engagement, and safety outcomes. Journal of Applied Psychology, 96, 71-94. doi: 10.1037/a0021484

Neal, A., \& Griffin, M. A. (2006). A study of the lagged relationships among safety climate, safety motivation, safety behavior, and accidents at the individual and group levels. Journal of Applied Psychology, 91, 946-953. doi: 10.1037/0021-9010.91.4.946

Occupational Safety and Health Administration (2015). Commonly used statistics. Retrieved on December 14, 2016 from https://www.osha.gov/oshstats/commonstats.html.

Peterson, C., \& Seligman, M. E. P. (1983). Learned helplessness and victimization. Journal of Social Issues, 39, 103-116. doi: 10.1111/j.1540-4560.1983.tb00143.x

Probst, T. M., Brubaker, T. L., \& Barsotti, A. (2008). Organizational injury rate underreporting: The moderating effect of organizational safety climate. Journal of Applied Psychology, 93, 1147-1154. doi: 10.1037/0021-9010.93.5.1147

Roth, S., \& Kubal, L. (1975). Effects of noncontingent reinforcement on tasks of differing importance: Facilitation and learned helplessness. Journal of Personality and Social Psychology, 32, 680-691. doi: 10.1037/0022-3514.32.4.680

Seibert, S. E., Wang, G., \& Courtright, S. H. (2011). Antecedents and consequences of psychological and team empowerment in organizations: A meta-analytic review. Journal of Applied Psychology, 96, 981-1003. doi: 10.1037/a0022676

Seligman, M. E. (1972). Learned helplessness. Annual Review of Medicine, 23, 407-412. doi: 10.1146/annurev.me.23.020172.002203

Seligman, M. E. (1975). Helplessness: On depression, development, and death. New York: WH Freeman/Times Books/Henry Holt \& Co. 
Spector, P. E., Fox, S., Penney, L. M., Bruursema, K., Goh, A., \& Kessler, S. (2006). The dimensionality of counterproductivity: Are all counterproductive behaviors created equal? Journal of Vocational Behavior, 68, 446-460. doi: 10.1016/j.jvb.2005.10.005

Spreitzer, G. (1995). Psychological empowerment in the workplace: Dimensions, measurement, and validation. Academy of Management Journal, 38, 1442-1465. doi: 10.2307/256865

Thomas, K., \& Velthouse, B. (1990). Cognitive elements of empowerment: An “interpretive” model of intrinsic task motivation. Academy of Management Review, 15, 668-681. doi: 10.5465/AMR.1990.4310926

Time Inc. (2014). The 10 most dangerous jobs and how much they pay. Retrieved on December 13, 2015 from http://time.com/money/3430567/most-dangerous-jobs-what-pay

Türkiye Odalar ve Borsalar Birliği (2013). Türkiye demir ve demirdışı metaller meclisi sektör raporu [Turkish iron and other metals council sector report]. Retrieved on January 25, 2016 from http://www.tobb.org.tr/Documents/yayinlar/2014/Demir\%20ve\%20Demir\%20D\%C4\%B1 \%C5\%9F\%C4\%B1\%20Rapor\%20web.pdf.

van Dyck, C., Frese, M., Baer, M., \& Sonnentag, S. (2005). Organizational error management culture and its impact on performance: A two-study replication. Journal of Applied Psychology, 90, 1228-1240. doi: 10.1037/0021-9010.90.6.1228

Weiss, H. M., \& Rupp, D. E. (2011). Experiencing work: An essay on a person-centric work psychology. Industrial and Organizational Psychology, 4, 83-97. doi: 10.1111/j.17549434.2010.01302.x 
Westaby, J. D., \& Lowe, J. K. (2005). Risk-taking orientation and injury among youth workers: Examining the social influence of supervisors, coworkers, and parents. Journal of Applied Psychology, 90, 1027-1035. doi: 10.1037/0021-9010.90.5.1027

World Steel Association (2015). World steel in figures 2015. Retrieved on December 26, 2015 from https://www.worldsteel.org/dms/internetDocumentList/bookshop/World-Steel-inFigures-2014/document/World\%20Steel\%20in\%20Figures\%202014\%20Final.pdf

Wortman, C. B., \& Brehm, J. W. (1975). Responses to uncontrollable outcomes: An integration of reactance theory and the learned helplessness model. Advances in Experimental Social Psychology, 8, 277-336. doi: 10.1016/S0065-2601(08)60253-1

Young, C. A., \& Corsun, D. L. (2009). Burned! The impact of work aspects, injury, and job satisfaction on unionized cooks' intentions to leave the cooking occupation. Journal of Hospitality \& Tourism Research, 34, 78-102. doi: 10.1177/1096348009349816

Zimmerman, R. D., Swider, B. W., Woo, S. E., \& Allen, D. G. 2016). Who withdraws? Psychological individual differences and employee withdrawal behaviors. Journal of Applied Psychology, 101, 498-519. doi: 10.0.4.13/apl0000068

Zohar, D. (2000). A group-level model of safety climate: Testing the effect of group climate on microaccidents in manufacturing jobs. Journal of Applied Psychology, 85, 587-596. doi: 10.1037/0021-9010.85.4.587 
Table 1

Means, Standard Deviations, and Intercorrelations among Variables

\begin{tabular}{|c|c|c|c|c|c|c|c|c|c|c|c|c|}
\hline Variable & Mean & SD & 1 & 2 & 3 & 4 & 5 & 6 & 7 & 8 & 9 & 10 \\
\hline 1. Accident involvement (T3E) & .19 & .39 & & & & & & & & & & \\
\hline 2. Empowerment (T2E) & 3.93 & .61 & -.04 & & & & & & & & & \\
\hline 3. Safety compliance (T3E) & 4.29 & .60 & .04 & $.22 * *$ & & & & & & & & \\
\hline 4. Employee withdrawal (T4M) & 1.69 & .64 & $.11^{*}$ & -.04 & $-.12 *$ & & & & & & & \\
\hline 5. Production deviance (T4M) & 1.90 & .70 & $.14^{* *}$ & -.02 & .02 & $.52 * *$ & & & & & & \\
\hline 6. Sabotage (T4M) & 1.60 & .50 & $.13^{*}$ & -.03 & $-.11 *$ & $.67 * *$ & $.52 * *$ & & & & & \\
\hline 7. Risk taking (T1E) & 2.94 & .82 & .03 & -.04 & $-.20 * *$ & -.00 & .00 & -.01 & & & & \\
\hline 8. Safety climate (T3E) & 3.99 & .72 & .01 & $.22 * *$ & $.57 * *$ & $-.13 *$ & .02 & -.08 & $-.17 * *$ & & & \\
\hline 9.Level (T1E) & 1.17 & .46 & -.08 & $.25 * *$ & .07 & .04 & .09 & -.02 & -.02 & $.17 * *$ & & \\
\hline 10.Tenure (T1E) & 9.74 & 7.94 & -.05 & $.20 * *$ & $.14^{* *}$ & $-.14 * *$ & -.08 & $-.17 * *$ & .01 & $.11^{*}$ & $.16^{* *}$ & \\
\hline 11.Education (T1E) & 4.68 & 2.00 & .05 & .09 & $.19^{* *}$ & -.03 & $.10^{*}$ & .02 & -.03 & $.16^{* *}$ & $.30 * *$ & $-.30 * *$ \\
\hline
\end{tabular}

$n=392$. Accident involvement was coded as $0=$ no accidents in the past 6 months, $1=$ at least one accident reported in the past 6 months. Tenure is organizational tenure in years. Education ranges between 0 and 9. Level is level in hierarchy and was coded from 1 to 3. T1, T2, T3, T4 refer to timing of measurement and are separated by one month each. E and M refer to Employee and Manager surveys.

$* p<.05$; ** $p<.01$. 
Table 2

Tests of Hypotheses 1 and 2

\begin{tabular}{|c|c|c|c|c|c|c|c|c|c|c|c|c|}
\hline & \multicolumn{6}{|c|}{$\begin{array}{c}\text { Safety Compliance } \\
\end{array}$} & \multicolumn{6}{|c|}{$\begin{array}{c}\text { Employee Withdrawal } \\
\end{array}$} \\
\hline & \multicolumn{3}{|c|}{ Model 1 } & \multicolumn{3}{|c|}{ Model 2} & \multicolumn{3}{|c|}{ Model 1 } & \multicolumn{3}{|c|}{ Model 2} \\
\hline Variable & Estimate & SE & $\mathrm{t}$ & Estimate & $\mathrm{SE}$ & $\mathrm{t}$ & Estimat & SE & $\mathrm{T}$ & Estimate & & $\mathrm{t}$ \\
\hline Intercept & 4.18 & .17 & $25.37 * *$ & 4.19 & .17 & $25.15^{* *}$ & 1.44 & .81 & 1.78 & 1.48 & 1.12 & 1.32 \\
\hline Risk taking & -.06 & .02 & $-2.91 * *$ & -.06 & .02 & $-2.92 * *$ & -.03 & .03 & -.87 & -.03 & .03 & -.90 \\
\hline Safety climate & .12 & .04 & $3.38 * *$ & .12 & .04 & $3.39 * *$ & .00 & .04 & -.01 & .00 & .04 & .07 \\
\hline Level & -.13 & .09 & -1.48 & -.14 & .09 & -1.52 & .03 & .26 & .12 & -.00 & .26 & -.01 \\
\hline Tenure & .00 & .01 & -.07 & .00 & .01 & -.07 & -.01 & .01 & -1.40 & -.01 & .01 & -1.40 \\
\hline Education & .01 & .01 & 1.13 & .01 & .01 & 1.12 & -.02 & .01 & $-2.11^{*}$ & -.03 & .01 & $-2.48 *$ \\
\hline Accident involvement & -.10 & .06 & -1.78 & -.10 & .06 & -1.80 & .14 & .07 & $1.98 *$ & .14 & .06 & $2.18^{*}$ \\
\hline $\begin{array}{l}\text { Psychological } \\
\text { empowerment }\end{array}$ & .04 & .02 & 1.81 & .05 & .02 & $2.16^{*}$ & .03 & .05 & .50 & .09 & .05 & 1.77 \\
\hline $\begin{array}{l}\text { Accident } \mathrm{x} \\
\text { empowerment }\end{array}$ & & & & -.03 & .05 & -.62 & & & & -.27 & .09 & $-3.04 * *$ \\
\hline $\begin{array}{l}\text { Deviance } \\
(-2 * \log \text { likelihood })\end{array}$ & \multirow{3}{*}{\multicolumn{3}{|c|}{7261.99}} & \multicolumn{3}{|c|}{7264.33} & \multicolumn{3}{|c|}{7548.20} & \multicolumn{3}{|c|}{7540.56} \\
\hline$\Delta \mathrm{df}$ & & & & \multirow{2}{*}{\multicolumn{3}{|c|}{$\begin{array}{c}2 \\
-234\end{array}$}} & & & & \multicolumn{3}{|c|}{2} \\
\hline Deviance change & & & & & & & \multirow{2}{*}{\multicolumn{3}{|c|}{$2.2 \%$}} & \multirow{2}{*}{\multicolumn{3}{|c|}{$3.6 \%$}} \\
\hline$R^{2}$ & \multicolumn{3}{|c|}{$6.7 \%$} & \multicolumn{3}{|c|}{$6.7 \%$} & & & & & & \\
\hline
\end{tabular}

$n=392$. Safety compliance is employee rated, and employee withdrawal is manager rated. Accident involvement was coded as $0=$ no accidents in the past 6 months, $1=$ at least one accident in the past 6 months. Level is level in hierarchy and was coded from 1 to 3 . Tenure is organizational tenure in years. Education ranges between 0 and 9 . Results are within-level estimates.

$* p<.05$; ** $p<.01$. 
Table 3

Tests of Hypothesis $3 a$ and $3 b$

\begin{tabular}{|c|c|c|c|c|c|c|c|c|c|c|c|c|}
\hline \multirow[b]{3}{*}{ Variable } & \multicolumn{6}{|c|}{$\begin{array}{l}\text { Production Deviance } \\
\end{array}$} & \multicolumn{6}{|c|}{ Sabotage } \\
\hline & \multicolumn{3}{|c|}{ Model 1} & \multicolumn{3}{|c|}{ Model 2} & \multicolumn{3}{|c|}{ Model 1} & \multicolumn{3}{|c|}{ Model 2} \\
\hline & Estimate & $\mathrm{SE}$ & $\mathrm{t}$ & Estimate & SE & $\mathrm{t}$ & Estimate & SE & $\mathrm{t}$ & Estimate & $\mathrm{SE}$ & $\mathrm{t}$ \\
\hline Intercept & 1.58 & 1.09 & 1.45 & 1.72 & 1.42 & 1.21 & 1.36 & .88 & 1.54 & 1.39 & 1.03 & 1.35 \\
\hline Risk taking & -.01 & .03 & -.17 & -.01 & .03 & -.32 & -.03 & .03 & -.99 & -.03 & .03 & -1.01 \\
\hline Safety climate & .01 & .05 & .28 & .02 & .05 & .35 & .04 & .03 & 1.05 & .04 & .03 & 1.07 \\
\hline Level & .11 & .19 & .59 & .07 & .18 & .39 & -.21 & 12 & -1.59 & -.23 & .13 & -1.80 \\
\hline Tenure & -.01 & .01 & -.89 & -.00 & .01 & -.87 & -.01 & .00 & -1.69 & -.01 & .00 & -1.71 \\
\hline Education & -.01 & .01 & -1.20 & -.02 & .01 & -1.55 & .00 & .01 & .07 & -.00 & .01 & -.14 \\
\hline $\begin{array}{l}\text { Accident } \\
\text { involvement }\end{array}$ & .15 & .07 & $2.09 *$ & .14 & .06 & $2.27 *$ & .09 & .05 & 1.86 & .09 & .05 & 1.91 \\
\hline $\begin{array}{l}\text { Psychological } \\
\text { empowerment }\end{array}$ & -.02 & .05 & -.47 & .04 & .04 & 1.10 & .05 & .03 & 1.47 & .08 & .03 & $2.60 * *$ \\
\hline $\begin{array}{l}\text { Accident } \mathrm{x} \\
\text { empowerment }\end{array}$ & & & & -.28 & .11 & $-2.53 *$ & & & & -.13 & .06 & $-2.16^{*}$ \\
\hline $\begin{array}{l}\text { Deviance } \\
(-2 * \log \\
\text { likelihood) }\end{array}$ & & 7577.18 & & & 7569.84 & & & 288.77 & & & 7284.01 & \\
\hline$\Delta \mathrm{df}$ & & & & & 2 & & & & & & 2 & \\
\hline $\begin{array}{l}\text { Deviance } \\
\text { change }\end{array}$ & & & & & $7.35 *$ & & & & & & 4.76 & \\
\hline$R^{2}$ & & $1.5 \%$ & & & $3.1 \%$ & & & $4.1 \%$ & & & $4.8 \%$ & \\
\hline
\end{tabular}

$n=392$. Accident involvement was coded as $0=$ no accidents in the past 6 months, $1=$ at least one accident in the past 6 months. Level is level in hierarchy and was coded from 1 to 3 . Tenure is organizational tenure in years. Education ranges between 0 and 9 . Results are within-level estimates.

$* p<.05 ; * * p<.01$. 


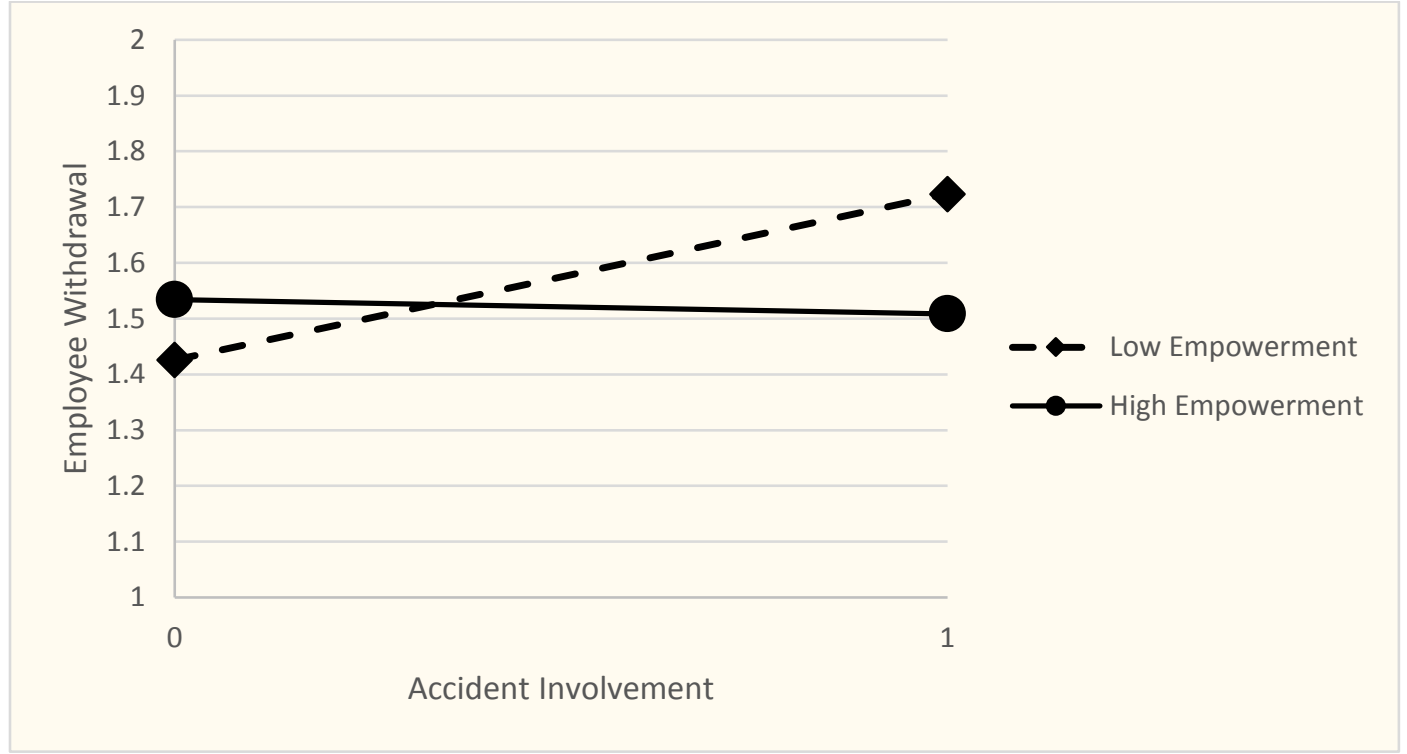

Figure 1. Interaction of accident involvement and psychological empowerment to predict withdrawal (manager rated). 


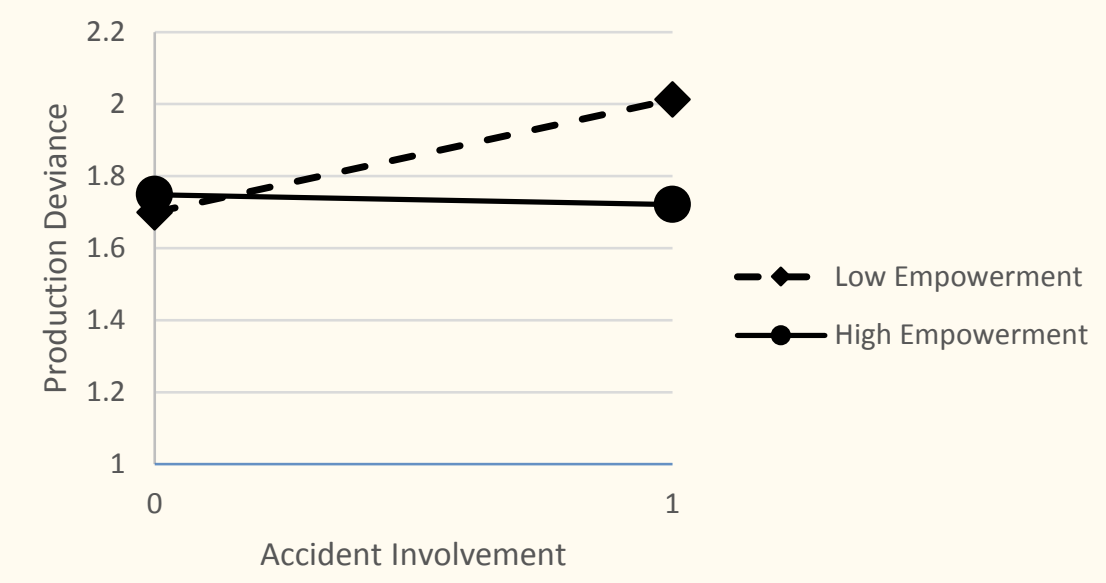

Figure 2a. Interaction of accident involvement and psychological empowerment to predict manager rated production deviance.

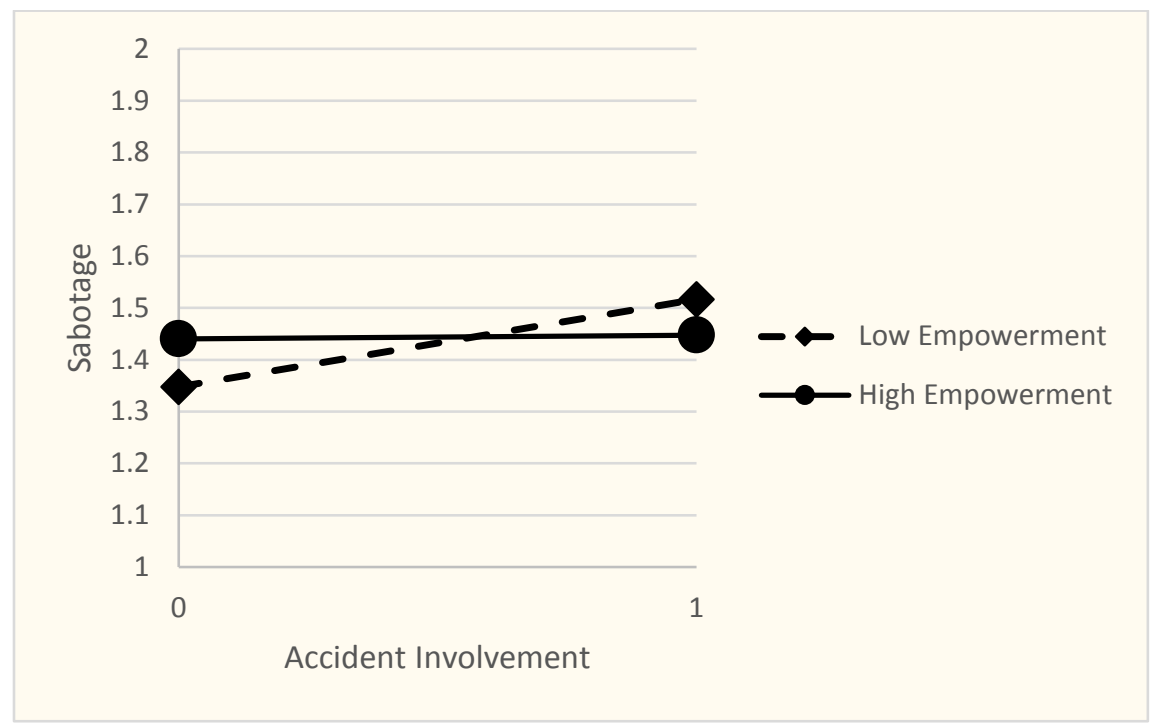

Figure $2 b$. Interaction of accident involvement and psychological empowerment to predict manager rated sabotage. 